\title{
Inconsistencies between alcohol screening results based on AUDIT-C scores and reported drinking on the AUDIT-C questions: prevalence in two US national samples
}

Kate E Delaney ${ }^{4}$, Amy K Lee ${ }^{1,6}$, Gwen T Lapham ${ }^{1,6}$, Anna D Rubinsky ${ }^{5,7}$, Laura J Chavez ${ }^{1,2}$ and Katharine A Bradley ${ }^{1,2,3,56^{*}}$

\begin{abstract}
Background: The AUDIT-C is an extensively validated screen for unhealthy alcohol use (i.e. drinking above recommended limits or alcohol use disorder), which consists of three questions about alcohol consumption. AUDIT-C scores $\geq 4$ points for men and $\geq 3$ for women are considered positive screens based on US validation studies that compared the AUDIT-C to "gold standard" measures of unhealthy alcohol use from independent, detailed interviews. However, results of screening - positive or negative based on AUDIT-C scores - can be inconsistent with reported drinking on the AUDIT-C questions. For example, individuals can screen positive based on the AUDIT-C score while reporting drinking below US recommended limits on the same AUDIT-C. Alternatively, they can screen negative based on the AUDIT-C score while reporting drinking above US recommended limits. Such inconsistencies could complicate interpretation of screening results, but it is unclear how often they occur in practice.
\end{abstract}

Methods: This study used AUDIT-C data from respondents who reported past-year drinking on one of two national US surveys: a general population survey $(\mathrm{N}=26,610)$ and a Veterans Health Administration (VA) outpatient survey ( $N=467,416)$. Gender-stratified analyses estimated the prevalence of AUDIT-C screen results—positive or negative screens based on the AUDIT-C score-that were inconsistent with reported drinking (above or below US recommended limits) on the same AUDIT-C.

Results: Among men who reported drinking, $13.8 \%$ and $21.1 \%$ of US general population and VA samples, respectively, had screening results based on AUDIT-C scores (positive or negative) that were inconsistent with reported drinking on the AUDIT-C questions (above or below US recommended limits). Among women who reported drinking, $18.3 \%$ and $20.7 \%$ of US general population and VA samples, respectively, had screening results that were inconsistent with reported drinking.

Limitations: This study did not include an independent interview gold standard for unhealthy alcohol use and therefore cannot address how often observed inconsistencies represent false positive or negative screens.

Conclusions: Up to $21 \%$ of people who drink alcohol had alcohol screening results based on the AUDIT-C score that were inconsistent with reported drinking on the same AUDIT-C. This needs to be addressed when training clinicians to use the AUDIT-C.

Keywords: AUDIT-C, Brief intervention, Unhealthy alcohol use, Alcohol screening, Heavy episodic drinking

\footnotetext{
*Correspondence: bradley.k@ghc.org

'VA HSR\&D Denver-Seattle Center of Innovation for Veteran-Centered and Value-Driven Care, Seattle, WA, USA

${ }^{2}$ Department of Health Services, University of Washington, Seattle, WA, USA

Full list of author information is available at the end of the article
} 


\section{Background}

Alcohol screening and brief interventions (BIs) are effective in reducing primary care patients' alcohol consumption [1-4]. BIs have been proven effective for patients with unhealthy alcohol use, defined as drinking at levels known to adversely impact health ("risky drinking") and/or meeting diagnostic criteria for alcohol use disorders (AUD) (Table 1) [5]. The US Preventive Services Task Force (USPSTF) recommends routine implementation of alcohol screening and BIs in primary care to reduce unhealthy alcohol use $[3,4]$.

Several brief screens for identifying patients with unhealthy alcohol use are recommended based on validation studies $[3,4]$. These validation studies have identified optimal screening thresholds for unhealthy alcohol use by comparing alcohol screens to a gold standard measure of unhealthy alcohol use obtained from independent, detailed interview assessments of both alcohol consumption and symptoms of AUD [6,7]. The optimal screening thresholds maximize both sensitivity and specificity for unhealthy alcohol use based on the gold standard measure, irrespective of whether patients report risky drinking and/or symptoms of AUD on the brief alcohol screen.

The 3-item Alcohol Use Disorders Identification TestConsumption (AUDIT-C) questionnaire is one of several brief screens for unhealthy alcohol use recommended by the USPSTF and consists of the first three questions of the World Health Organization's 10-item AUDIT, which ask about alcohol consumption [8]. The AUDIT-C, scored 0-12 points, is a scaled marker of alcohol consumption, as well as the risk of AUD and other complications of drinking [9-21]. The AUDIT-C has been extensively validated in a wide variety of settings and populations, including primary care patients and general population samples in the US, Belgium, Spain, Germany, Brazil, and Taiwan $[6,7,22-32]$, and is increasingly being integrated into routine preventive care [3,33-35]. The optimal AUDIT-C thresholds for unhealthy alcohol use in the US, based on comparison to detailed gold standard interviews, are $\geq 4$ points for men and $\geq 3$ points for women $[6,7,22,36]$.

However, a potential limitation of the AUDIT-C is that there can be inconsistencies between the AUDIT-C screen result-positive or negative based on the total AUDIT-C score ( $\geq 4$ and $\geq 3$ points for men and women, respectively) - and whether respondents report drinking above or below US recommended drinking limits on the AUDIT-C questions [33]. These inconsistencies can happen in two general ways: patients can screen positive for unhealthy alcohol use based on the AUDIT-C score while reporting drinking below US recommended limits or they can screen negative based on the AUDIT-C score while reporting drinking above recommended drinking limits. As above, the optimal thresholds for a positive AUDIT-C score were determined by validation studies based on detailed, independent interviews about alcohol consumption and AUD symptoms, irrespective of these inconsistencies. Moreover, these inconsistencies are not necessarily "false positive" or "false negative" screens because the individual AUDIT-C questions underestimate typical drinking [37] and do not assess AUD symptoms. Nevertheless, these inconsistencies can be perceived by clinicians to be false positive or false negative screens and may result in uncertainty about whether or not to offer a BI for unhealthy alcohol use. However, no prior study to our knowledge has assessed whether these inconsistencies are common, or how often they occur in practice. If they were common, clinicians would need to be prepared to interpret them and provide further assessment of alcohol use and/or offer BIs appropriately.

\section{Table 1 Definitions used in this report and US recommended drinking limits [39]}

Study definition of drinking above recommended limits:

Heavy episodic drinking:

Alcohol use disorder:

Unhealthy alcohol use:

Gender-specific US recommended drinking limits: $\geq 5$ drinks $^{*}$ in any single day ${ }^{* *}$ and/or exceeding gender-specific US recommendations for maximum average number of drinks ${ }^{*}$ per week

Drinking above recommended daily drinking limits $(\geq 5$ drinks in any single day, in this report; gender-specific US recommended limits below)

DSM-IV diagnosis of alcohol abuse or dependence

Drinking above recommended drinking limits and/or alcohol use disorder diagnosis

$$
\begin{gathered}
\text { Maximum number of drinks* } \\
\text { in any single day } \\
4 \text { drinks } \\
3 \text { drinks }
\end{gathered}
$$

Maximum average number of drinks" per week 14 drinks 7 drinks

Questions used to define drinking above US recommended limits

$$
\begin{array}{ll}
>\text { Weekly limits } & \text { AUDIT-C Questions \#1-2 } \\
\text { Heavy episodic drinking } & \text { AUDIT-C Questions \#2-3 }
\end{array}
$$

\footnotetext{
*Drinks refer to standard-sized drinks: $12 \mathrm{oz}$. beer, $5 \mathrm{oz}$. wine, or $1.5 \mathrm{oz}$. liquor.

** The same definition of heavy episodic drinking was used in men and women because the AUDIT-C questions used in this study did not assess drinking 4 or more drinks on an occasion.
} 
This study described how often the results of screening with the AUDIT-C-positive or negative for unhealthy alcohol use based on the AUDIT-C score-are inconsistent with whether the individual's reported drinking on the AUDIT-C is above or below US recommended drinking limits (Table 1). We determine the prevalence of these inconsistencies in two national US samples of individuals who reported drinking alcohol in the past year.

\section{Methods}

\section{Overview}

This study used two national US surveys that included the AUDIT-C to describe how often the results of screeningpositive or negative screen based on the total AUDIT-C score-were inconsistent with the reported drinking-above or below US recommended drinking limits-on the same AUDIT-C. This study is therefore different from validation studies of the AUDIT-C, which compare the AUDIT-C to independent, gold-standard measures of unhealthy alcohol use. Instead, the present study was designed to assess how often inconsistencies between the results of the screen and reported drinking on the AUDIT-C questions occur in large samples of people who drink alcohol.

\section{Data sources and study population US general population sample}

This study used secondary data from the 2001-2002 National Epidemiologic Survey on Alcohol and Related Conditions (NESARC), which evaluated the prevalence of alcohol use disorders and related disabilities in a general US population sample of 43,093 civilian, non-institutionalized adults 18 years of age and older using computer-assisted personal interviews (81\% response rate) [38]. Young adults (18-24), non-Hispanic blacks, and Hispanics were oversampled to facilitate subgroup analyses [38]. NESARC participants were asked if they had had at least one drink of alcohol in their entire lives and, if so, if they had at least one drink in the past 12 months. If participants answered no to either question, they were considered non-drinkers by NESARC and were not asked about past-year alcohol use. Non-drinkers represented $34.6 \%$ of the NESARC sample, with $17.3 \%$ lifetime abstainers and $17.3 \%$ former drinkers [39]. Respondents who reported past-year drinking were asked about their alcohol use in the past year using a version of the AUDIT-C that has been previously validated (Table 2) [23,24].

NESARC participants who were past-year drinkers and responded to all three questions of the AUDIT-C (99.4\% of drinkers) were eligible for this study and are referred to as the "US general population sample" hereafter.

\section{VA outpatient sample}

This study also used secondary data from the VA's national outpatient satisfaction survey (2004-2007), called
Table 2 AUDIT-C versions used in this study

\begin{tabular}{|c|c|}
\hline \multicolumn{2}{|c|}{ US General Population Sample (2001-2002 NESARC Surveys) [24] } \\
\hline AUDIT-C Question \#1 & $\begin{array}{l}\text { During the last } 12 \text { months, about how } \\
\text { often did you drink ANY alcoholic beverage? } \\
\text { Never (0); } 1 \text { or } 2 \text { times in the last year (1); } 3 \text { to } 6 \\
\text { times in the last year (1); } 7 \text { to } 11 \text { times in the last } \\
\text { year (1); Once a month (1); } 2 \text { to } 3 \text { times a month (2); } \\
\text { Once a week (2); } 2 \text { times a week (3); } 3 \text { to } 4 \text { times } \\
\text { a week (3); Nearly every day (4); Every day (4) }\end{array}$ \\
\hline
\end{tabular}

AUDIT-C Question \#2 Counting all types of alcohol combined, how many drinks did you USUALLY have on days when you drank during the last

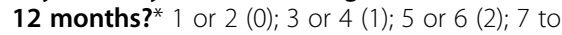
9 (3); 10 or more (4)

AUDIT-C Question \#3 During the last 12 months, about how often did you drink FIVE OR MORE drinks in a single day? Never (0); 1 or 2 times in the last year (1); 3 to 6 times in the last year (1); 7 to 11 times in the last year (1); Once a month (2); 2 to 3 times a month (2); Once a week (3); 2 times a week (3); 3 to 4 times a week (3); Nearly every day (4); Every day (4)

VA Outpatient Sample (2004-2007 SHEP Surveys)

AUDIT-C Question \#1 How often have you had a drink containing alcohol in the past 12 months? Consider a "drink" to be a can or bottle of beer, a glass of wine, a wine cooler, or one cocktail or a shot of hard liquor (like scotch, gin, vodka). Never (0); Monthly or less (1); 2 to 4 times a month (2); 2 to 3 times a week (3); 4 to 5 times a week (4); 6 or more times a week (4)

AUDIT-C Question \#2 How many drinks containing alcohol did you have on a typical day when you were drinking in the past 12 months? 0 drinks (Did not drink in the past 12 months) (0 points); 1 to 2 drinks (0); 3 to 4 drinks (1); 5 to 6 drinks (2); 7 to 9 drinks (3); 10 or more drinks (4).

AUDIT-C Question \#3 How often did you have 6 or more drinks on one occasion in the past 12 months? Never (0 points); Less than monthly (1); Monthly (2); Weekly (3); Daily or almost daily (4).

*Question \#2 in the NESARC AUDIT-C was based on an open-ended response and then mapped onto these AUDIT-C response options.

the Survey of Healthcare Experiences of Patients (SHEP). SHEP is conducted by the VA Office of Analytics and Business Intelligence and is mailed monthly to a random sample of outpatients who have had a past-month outpatient VA visit and who have not completed SHEP in the prior 12 months. Of those who were mailed SHEP during the study period, 1,016,774 responded, and a $70 \%$ response rate has been reported previously over a similar time frame [40].

SHEP respondents were eligible for the present study if they completed all three AUDIT-C questions (87.3\% of responders) and reported drinking alcohol in the past year (52.7\% of AUDIT-C completers) [6,33]. This sample is referred to as the "VA outpatient sample." Past-year non-drinkers were excluded so that the sample would be comparable to the US general population sample. 


\section{Measures}

The AUDIT-C

Each question of the AUDIT-C is scored 0 to 4 points, and questions are summed for a total AUDIT-C score of 0-12 points, with 0 indicating no alcohol use in the last year and 12 indicating the most severe unhealthy alcohol use. Several different versions of the AUDIT-C have been evaluated in the US and the same cut-points for a positive screen for unhealthy alcohol use ( $\geq 4$ points for men and $\geq 3$ points for women) have been validated in clinical validation studies irrespective of whether the AUDIT-C specified a past-year time frame or standard US drink sizes, or whether standard wording and/or standard response options for questions $1-3$ of the original AUDIT were used $[6,7,22,36]$. The cut-point for women was also optimal irrespective of whether the third AUDIT-C question asked about the frequency of drinking 4 or more or 6 or more drinks on an occasion for women [22].

The two versions of the AUDIT-C used in this study differed slightly (Table 2), but both versions have been validated for identifying individuals with past-year unhealthy alcohol use using independent, in-depth interviews about alcohol consumption and AUD to define the gold standard of unhealthy alcohol use $[6,7,22,24]$. On both AUDIT-C versions, each AUDIT-C question is scored from $0-4$, and the scores are summed for a total score of 0-12 (Additional file 1: Appendix A).

\section{Screen results based on the total AUDIT-C score}

Respondents were considered to screen positive for unhealthy alcohol use (on either the NESARC or SHEP versions of the AUDIT-C) if their total AUDIT-C score was $\geq 4$ points for men or $\geq 3$ points for women and negative if their total AUDIT-C score was 1-3 points for men and 1-2 points for women. These were the optimal thresholds for unhealthy alcohol use in VA outpatient samples $[7,22]$ and non-VA primary care patients [6] and among NESARC participants who reported drinking [23,24].

\section{Reported drinking above US recommended limits on the AUDIT-C questions}

Individuals were considered to report drinking above US recommended limits on the AUDIT-C if they reported (1) heavy episodic drinking defined as drinking above recommended drinking limits for any single day $(\geq 5$ drinks in a day) on AUDIT-C Questions \#2 or \#3 or (2) drinking above average weekly limits ( $>14$ drinks a week for men or $>7$ drinks a week for women) based on AUDIT-C Questions \#1 and \#2. Although NIAAA recommendations include gender-specific limits for heavy episodic drinking (Table 1), this study used a single definition of heavy episodic drinking ( $\geq 5$ drinks in a day) for both men and women because the SHEP survey AUDIT-C did not include gender-specific questions about heavy episodic drinking (i.e. AUDIT-C Question \#3). Respondents' average weekly consumption was calculated using the lower end of response ranges for reported number of drinking days per week (Question \#1) and the number of drinks per typical drinking day (Question \#2) to conservatively estimate the lowest possible reported weekly consumption. For example, an individual reporting drinking 2 to 4 times per month and 5 to 6 drinks per drinking occasion would be estimated to drink 5 drinks twice a month, or 2.5 drinks per week on average. A conservative interpretation of response ranges was used because instances where patients who screen positive on the AUDIT-C but who report drinking below recommended drinking limits have been most bothersome to clinicians [33]. Therefore, when estimating individuals' consumption based on the individual AUDIT-C questions, we were interested in identifying all possible instances of reported drinking within recommended drinking limits and having a positive AUDIT-C screen.

\section{Other measures}

Age, gender, education, race/ethnicity, and marital status were available for both the US general population and VA outpatient samples.

\section{Analyses}

Inconsistent response patterns were defined as AUDIT-C response patterns yielding screening results based on the AUDIT-C score (positive or negative) that were inconsistent with reported drinking (below or above US recommended limits). All analyses were stratified by gender: male drinkers were evaluated separately from female drinkers. Inconsistent response patterns included those in which: a) the AUDIT-C screen was positive but the responses to the AUDIT-C questions indicated drinking within US recommended limits; and b) the AUDIT-C screen was negative but the responses to the AUDIT-C questions indicated drinking above US recommended limits. Descriptive statistics were used to evaluate the proportion of male and female drinkers in each sample (US general population sample and VA outpatient sample) who had inconsistent response patterns.

All analyses were conducted in Stata 11.2 [41]. This study received approval and waivers of written informed consent and HIPAA authorization from the VA Puget Sound Health Care System Institutional Review Board.

\section{Results}

The US general population sample included 26,610 drinkers and the VA outpatient sample included 467,416 drinkers who met eligibility criteria for this study. Table 3 shows available demographic characteristics of the study samples. The VA sample was generally older and predominantly male. Despite age and gender differences, the prevalence of positive screens in these two samples of individuals 
Table 3 Demographics of the US general population and VA outpatient samples

\begin{tabular}{|c|c|c|c|c|}
\hline \multirow[b]{2}{*}{ Demographic characteristic } & \multicolumn{2}{|c|}{$\begin{array}{l}\text { US general } \\
\text { population } \\
\text { sample } \\
(\mathrm{N}=26,610)\end{array}$} & \multicolumn{2}{|c|}{$\begin{array}{l}\text { VA outpatient } \\
\text { sample } \\
(\mathrm{N}=467,416)\end{array}$} \\
\hline & $\mathrm{n}$ & (\%) & $\mathbf{n}$ & (\%) \\
\hline \multicolumn{5}{|l|}{ Gender } \\
\hline Male & 12,856 & $(48.3)$ & 450,681 & $(96.4)$ \\
\hline Female & 13,754 & $(51.7)$ & 16,735 & (3.6) \\
\hline \multicolumn{5}{|l|}{ Age } \\
\hline $18-29$ & 6,073 & (22.8) & 4,477 & $(1.0)$ \\
\hline $30-39$ & 6,325 & $(23.8)$ & 8,619 & (1.8) \\
\hline $40-49$ & 5,699 & $(21.4)$ & 25,994 & (5.6) \\
\hline $50-59$ & 3,923 & $(14.7)$ & 102,506 & $(21.9)$ \\
\hline $60-69$ & 2,331 & (8.8) & 119,871 & $(25.6)$ \\
\hline 70-79 & 1,557 & (5.9) & 137,491 & $(29.4)$ \\
\hline $80+$ & 702 & $(2.6)$ & 68,458 & (14.6) \\
\hline \multicolumn{5}{|l|}{ Education* } \\
\hline High school/GED or less & 10,582 & $(39.8)$ & 211,501 & $(45.3)$ \\
\hline Some college/Associate's degree & 8,619 & $(32.4)$ & 146,837 & (31.4) \\
\hline College graduate or more & 7,409 & $(27.8)$ & 104,703 & $(22.4)$ \\
\hline \multicolumn{5}{|l|}{ Marital status* } \\
\hline Married/Living with significant other & 14,122 & $(53.1)$ & 305,107 & $(65.3)$ \\
\hline Widowed & 1,531 & $(5.8)$ & 39,939 & (8.5) \\
\hline Divorced/separated & 4,375 & $(16.4)$ & 90,794 & $(19.4)$ \\
\hline Never married & 6,582 & $(24.7)$ & 25,482 & (5.5) \\
\hline \multicolumn{5}{|l|}{ Race/ethnicity* } \\
\hline American Indian/Alaska Native & 410 & $(1.5)$ & 9,756 & (2.1) \\
\hline Asian/Native Hawaiian/Pacific Islander & 656 & $(2.5)$ & 3,723 & $(0.8)$ \\
\hline Black/African American & 4,126 & $(15.5)$ & 26,752 & (5.7) \\
\hline White & 16,542 & $(62.2)$ & 401,149 & $(85.8)$ \\
\hline Hispanic/Latino & 4,876 & $(18.3)$ & 20,819 & $(4.5)$ \\
\hline \multicolumn{5}{|l|}{$\begin{array}{l}\text { Positive AUDIT-C screens } \\
\text { (among drinkers) }\end{array}$} \\
\hline Male ( $\geq 4$ points) & 5,903 & $(45.9)$ & 202,003 & $(44.8)$ \\
\hline Female ( $\geq 3$ points) & 4,783 & $(34.8)$ & 6,202 & (37.1) \\
\hline
\end{tabular}

*Column totals of these demographic characteristics for VA Outpatient Sample do not total to $100 \%$ due to missing values.

who reported drinking in the past year were similar: $45 \%$ and $46 \%$ of male drinkers and $35 \%$ and $37 \%$ of female drinkers screened positive for unhealthy alcohol use at the optimal cut-points $(\geq 4$ points for men and $\geq 3$ points for women) in the US general population and VA outpatient samples, respectively. Ten response patterns were identified that yielded inconsistent results between screening based on the total AUDIT-C score (positive or negative) and reported drinking (above or below US recommended limits) on the AUDIT-C questions (Table 4).

\section{Prevalence of inconsistent response patterns}

Overall, among men in the US general population who reported drinking in the last year, 13.8\% (95\% CI 13.2-14.4) had inconsistent response patterns (Table 4). For men in the VA outpatient sample who reported drinking in the last year, 21.1\% (CI 20.9-21.1) had inconsistent response patterns. Among women, 18.3\% (CI 17.7-18.9) and 20.7\% (CI 20.1-21.3) had inconsistent response patterns in the US general population and VA outpatient samples, respectively (Table 4).

\section{Inconsistent response patterns in men \\ Positive AUDIT-C screens and report of drinking below US recommended limits}

Among male drinkers, positive AUDIT-C screens despite reporting drinking below recommended limits were the most common inconsistent response patterns, with $8.9 \%$ (CI 8.4-9.4) in the US general population sample and $15.8 \%$ (CI 15.6-15.8) in the VA outpatient sample (Table 4). The most common inconsistent response pattern among men in both the US general population and VA outpatient samples was report of drinking 4 or more days a week (4 points), 1 to 2 drinks per drinking day (0 points), and never engaging in heavy episodic drinking ( 0 points $)$ - or a 4-0-0 pattern (Table 4).

\section{Negative AUDIT-C screens and report of drinking above US recommended limits}

Among male drinkers in the US general population sample, 4.9\% (CI 4.6-5.3) had negative screens despite reporting heavy episodic drinking (Table 4). Among male drinkers in the VA sample, 5.3\% (CI 5.2-5.3) had negative AUDIT-C screens despite reporting heavy episodic drinking (Table 4).

\section{Inconsistent response patterns in women \\ Positive AUDIT-C screens and report of drinking below US recommended limits}

Among female drinkers, $17.5 \%$ (CI 16.8-18.1) of the US general population sample and $17.4 \%$ (CI 16.9-18.0) of the VA outpatient sample had positive AUDIT-C screens based on the total score despite reported drinking below recommended limits on the AUDIT-C questions (Table 4). The most common inconsistent response pattern among women in both the US general population and VA outpatient samples was drinking 2 to 3 times a week (3 points), 1 to 2 drinks per drinking day ( 0 points), and never engaging in heavy episodic drinking (0 points), or a 3-0-0 pattern (Table 4).

\section{Negative AUDIT-C screens and report of drinking above US} recommended limits

Among female drinkers, $0.8 \%$ (CI $0.7-1.0)$ of the US general population sample and $3.3 \%$ (CI 3.0-3.6) of the VA 
Table 4 Prevalence of inconsistency between screening results based on AUDIT-C scores and reported drinking on the same AUDIT-C in men and women

US general population sample

$(N=26,610)$
VA outpatient sample

$(\mathrm{N}=467,416)$

Men

Positive screen based on AUDIT-C score

\begin{tabular}{|c|c|c|c|c|c|c|c|}
\hline \multicolumn{4}{|c|}{ AUDIT-C score } & \multicolumn{4}{|c|}{$\%$ reporting $<$ recommended limits } \\
\hline Total & Q\#1 & Q\#2 & Q\#3 & $\%$ & $(95 \% \mathrm{Cl})$ & $\%$ & $(95 \% \mathrm{Cl})$ \\
\hline 4 & 3 & 1 & 0 & 2.3 & $(2.1-2.6)$ & 1.0 & $(1.0-1.0)$ \\
\hline 4 & 4 & 0 & 0 & 5.4 & $(5.1-5.8)$ & 12.9 & $(12.7-13.0)$ \\
\hline 5 & 4 & 1 & 0 & 1.1 & $(0.9-1.3)$ & 1.9 & $(1.8-1.9)$ \\
\hline \multicolumn{4}{|c|}{ All inconsistent positive screens } & $8.9^{*}$ & $(8.4-9.4)$ & 15.8 & $(15.6-15.8)$ \\
\hline \multicolumn{8}{|c|}{ Negative screen based on AUDIT-C score } \\
\hline \multicolumn{4}{|c|}{ AUDIT-C score } & \multicolumn{4}{|c|}{$\%$ reporting $>$ recommended limits } \\
\hline Total & Q\#1 & Q\#2 & Q\#3 & $\%$ & $(95 \% \mathrm{Cl})$ & $\%$ & $(95 \% \mathrm{Cl})$ \\
\hline 2 & 1 & 0 & 1 & 1.1 & $(0.9-1.2)$ & 2.0 & $(2.0-2.0)$ \\
\hline 3 & 1 & 1 & 1 & 2.0 & $(1.7-2.2)$ & 0.6 & $(0.6-0.6)$ \\
\hline 3 & 1 & 0 & 2 & 0 & - & 0.3 & $(0.3-0.3)$ \\
\hline 3 & 1 & 2 & 0 & 0 & - & 0.1 & $(0.01-0.1)$ \\
\hline 3 & 2 & 0 & 1 & 1.9 & $(1.7-2.2)$ & 2.3 & $(2.2-2.3)$ \\
\hline \multicolumn{4}{|c|}{ All inconsistent negative screens } & 4.9 & $(4.6-5.3)$ & 5.3 & $(5.2-5.3)$ \\
\hline \multicolumn{4}{|c|}{ All inconsistent negative \& positive screens } & 13.8 & $(13.2-14.4)$ & 21.1 & $(20.9-21.1)$ \\
\hline \multicolumn{8}{|c|}{ Women } \\
\hline \multicolumn{8}{|c|}{ Positive screen based on AUDIT-C score } \\
\hline \multicolumn{4}{|c|}{ AUDIT-C score } & \multicolumn{4}{|c|}{$\%$ reporting $<$ recommended limits $* *$} \\
\hline Total & Q\#1 & Q\#2 & Q\#3 & $\%$ & $(95 \% \mathrm{Cl})$ & $\%$ & $(95 \% \mathrm{Cl})$ \\
\hline 3 & 2 & 1 & 0 & 2.6 & $(2.4-2.9)$ & 1.5 & $(1.3-1.7)$ \\
\hline 3 & 3 & 0 & 0 & 8.2 & $(7.7-8.6)$ & 8.1 & $(7.7-8.5)$ \\
\hline 4 & 3 & 1 & 0 & 1.6 & $(1.4-1.8)$ & 0.6 & $(0.5-0.8)$ \\
\hline 4 & 4 & 0 & 0 & 5.0 & $(4.6-5.4)$ & 7.2 & $(6.8-7.6)$ \\
\hline \multicolumn{4}{|c|}{ All inconsistent positive screens } & $17.5^{*}$ & $(16.8-18.1)$ & 17.4 & $(16.9-18.0)$ \\
\hline \multicolumn{8}{|c|}{ Negative screen based on AUDIT-C score } \\
\hline \multicolumn{4}{|c|}{ AUDIT-C score } & \multicolumn{4}{|c|}{$\%$ reporting $>$ recommended limits } \\
\hline Total & Q\#1 & Q\#2 & Q\#3 & $\%$ & $(95 \% \mathrm{Cl})$ & $\%$ & $(95 \% \mathrm{Cl})$ \\
\hline 2 & 1 & 0 & 1 & 0.8 & $(0.7-1.0)$ & 3.3 & $(3.0-3.6)$ \\
\hline \multicolumn{4}{|c|}{ All inconsistent negative screens } & 0.8 & $(0.7-1.0)$ & 3.3 & $(3.0-3.6)$ \\
\hline \multicolumn{4}{|c|}{ All inconsistent negative $\&$ positive screens } & $18.3^{*}$ & $(17.7-18.9)$ & 20.7 & $(20.1-21.3)$ \\
\hline
\end{tabular}

*Numbers do not add up to totals due to rounding.

${ }^{* *}$ All negative screens with report of risky drinking were due to heavy episodic drinking ( $\geq 5$ drinks in a day).

sample had negative AUDIT-C screens despite reporting heavy episodic drinking (Table 4).

\section{Discussion}

Inconsistencies between results of alcohol screeningpositive or negative based on the total AUDIT-C scoreand reported drinking above or below US recommended limits on the same AUDIT-C screen can confuse clinicians [33]. However, the prevalence of these inconsistencies has not been previously described. In this study of individuals who reported drinking alcohol in the past year, $14 \%$ of men in the US general population sample and $21 \%$ of men in the VA outpatient sample, as well as $18 \%$ of women in the US general population sample and $21 \%$ of women in the VA outpatient sample had screening results based on the AUDIT-C score that were inconsistent with reported drinking on the same AUDIT-C. It is important for clinicians to be aware of these inconsistencies when offering screening and BI for unhealthy alcohol use.

The majority of inconsistent response patterns in both samples for men and women were positive screens based on the total AUDIT-C score despite report of drinking 
below US recommended limits on the same AUDIT-C. These results should not be assumed to be false positive screens, as patients may have under-reported their alcohol consumption or have an AUD (a diagnosis that does not require surpassing a drinking threshold). In a previous VA study, $46 \%$ of men who drank over 14 drinks a week based on an independent, gold standard interview reported drinking below 14 drinks a week on AUDIT-C questions \#1-2 [37]. Women may under-estimate their alcohol consumption even more often than men due to stigma associated with unhealthy alcohol use [42]. While patients may be accurately reporting their perception of their drinking on the AUDIT-C questions, they often under-estimate their true consumption compared to in-depth assessments that ask about different beverage types separately and take into account typical drink size and alcohol content [43]. For example, female VA patients report alcohol-related problems-tolerance, blackouts, and feeling the need to cut down-at total AUDIT-C scores as low as 3 [44], which are associated with report of drinking within US recommended limits (Table 4). If providers erroneously consider positive AUDIT-C screens as "false positives" and do not to provide BIs to such patients, some who would benefit from $\mathrm{BI}$ will be denied those benefits.

Although the majority of inconsistent screening patterns were positive AUDIT-C screens despite report of drinking below US recommended limits, up to 5\% of men and 3\% of women had negative AUDIT-C screens despite reported heavy episodic drinking (ie. drinking above recommended daily limits). This emphasizes the value of reviewing both the individual responses, particularly AUDIT-C question \#3 (frequency of heavy episodic drinking), as well as the total AUDIT-C score. Patients with heavy episodic drinking despite negative screens should ideally be offered BIs and advised about risks associated with heavy episodic drinking.

Even though providers using the AUDIT-C may face the above inconsistent response patterns, the AUDIT-C has certain advantages. The AUDIT-C has been validated as a screen for the spectrum of unhealthy alcohol use in diverse patient populations [6,7,22-32]. It also assesses whether patients drink at all (AUDIT-C scores $>0$ ) and identifies and documents their typical drinking patterns, an advantage over single-item screens [3]. In addition, the AUDIT-C score is a scaled marker of risk [9-21]. As a result, the AUDIT-C is commonly used [33-35].

Providers who work in healthcare settings that use the AUDIT-C therefore need to know how to adapt their BIs with patients who may have an inconsistent response pattern. Ideally, all patients who screen positive for unhealthy alcohol use should undergo further assessment regarding patterns of alcohol consumption and AUD symptoms [39]. One way of assessing alcohol-related symptoms would be to ask patients the other seven
AUDIT questions [8] - the AUDIT-C represents the first three questions-to identify alcohol-related consequences patients may report having experienced in the past year. Alternatively, because some systems may not have resources to conduct detailed assessments of all screenpositive patients, it might be appropriate to offer these patients BIs and reserve assessment for patients with higher AUDIT-C scores or those who do not respond to a BI [35]. For such individuals who report drinking below recommended limits despite screening positive, providers can recommend that patients maintain their drinking below recommended limits, specifically informing patients of these limits and standard drink sizes, and educate patients about the health consequences of exceeding these limits [3].

Patients with heavy episodic drinking despite negative screening results based on the AUDIT-C score can be identified by computerized algorithms in electronic health records or clinician review of responses to the AUDIT-C. These patients can be complimented on the fact that they drink below weekly limits, and provided with feedback on the risks of heavy episodic drinking, which is strongly associated with development of alcohol dependence [45,46] and a variety of other health concerns [12,47-57]. Finally, such patients can be offered explicit advice to limit the number of drinks they have in any single day.

\section{Limitations}

This study used two samples of drinkers, a US general population sample and a VA outpatient sample, but generalizability to other samples of drinkers is unknown. This study did not include an independent interview gold standard for unhealthy alcohol use and therefore cannot address how often observed inconsistencies represented false positive or negative screens. This study's conservative approach to defining reported drinking based on the lower end of response ranges could have underestimated reported drinking levels thereby potentially exaggerating inconsistencies between positive scores and reported drinking within limits. In addition, the AUDIT-C question about heavy episodic drinking may miss more women than men because the definition of reported drinking above recommended daily limits that was used in this study ( $\geq 5$ drinks in a day) is higher than the US gender-specific recommended daily limit for women ( $\geq 4$ drinks per day). Further, Question \#3 of the AUDIT-C used in the US general population sample asked how often the respondent drank 5 or more drinks in a single day, as is considered heavy episodic drinking in the US $[8,39]$, whereas the AUDIT-C in the VA outpatient sample (Table 2) asked about the frequency of 6 or more drinks on an occasion, as in the original validated AUDIT-C [7]. Differences in the sample selection for the two surveys as well as demographic characteristics could account for discrepancies observed in the exact prevalence of particular 
inconsistent response patterns. Nevertheless, these findings make it clear that screening positive based on AUDIT-C total score despite report of drinking below US recommended limits on AUDIT-C questions is not an uncommon occurrence in clinical or general population samples of drinkers.

\section{Conclusion}

The AUDIT-C is a widely used screen for unhealthy alcohol use that has been validated in various patient populations. However, individuals can screen positive based on the total AUDIT-C score despite report of drinking below US recommended limits on the AUDIT-C questions, and they can screen negative despite reporting heavy episodic drinking. This report of the prevalence of these inconsistencies-which is the first such report to our knowledge-demonstrates that some patterns are fairly common among individuals who drink alcohol. These results suggest that both the score and reported alcohol consumption should be taken into account when offering BIs after AUDIT-C screening.

\section{Additional file}

Additional file 1: Appendix A. Sensitivity and specificity of AUDIT-C for identifying unhealthy alcohol use (clinical samples) or drinking above US recommended limits (NESARC).

\section{Competing interests}

The authors declare that they have no competing interests.

\section{Authors' contributions}

Author KAB conceived of the study, obtained funding, and oversaw all aspects of the study. Authors ADR, GTL and LC undertook the statistical analyses. Authors KED and AL managed the literature searches and wrote the first draft of the paper. All authors have contributed to and have approved the final manuscript.

\section{Acknowledgments}

The research reported here was supported by the US Department of Veterans Affairs, Veterans Health Administration, Office of Research and Development, Health Services Research and Development Substance Use Disorders Quality Enhancement Research Initiative (QUERI) SHP 08-181.

\section{Disclaimer}

The views expressed in this article are those of the authors and do not necessarily reflect the position or policy of the US Department of Veterans Affairs, the US government, or any of the authors' institutions.

\footnotetext{
Author details

'VA HSR\&D Denver-Seattle Center of Innovation for Veteran-Centered and Value-Driven Care, Seattle, WA, USA. ${ }^{2}$ Department of Health Services, University of Washington, Seattle, WA, USA. ${ }^{3}$ Department of Medicine, University of Washington, Seattle, WA, USA. ${ }^{4}$ Internal Medicine Residency Program, Brown University, Providence RI, USA. ${ }^{5}$ Center of Excellence in Substance Abuse Treatment and Education (CESATE) Veterans Affairs (VA) Puget Sound Health Care System, Seattle, WA, USA. ${ }^{6}$ Group Health Research Institute, Seattle, WA, USA. ${ }^{7}$ HSR\&D Center for Innovation to Implementation (Ci2i), VA Palo Alto Health Care System, Menlo Park CA, USA.
}

Received: 20 December 2012 Accepted: 23 December 2013 Published: 27 January 2014

\section{References}

1. Kaner E, Beyer F, Dickinson H, Pienaar E, Campbell F, Schlesinger C, Heather $N$, Saunders J, Burnand B: Effectiveness of brief alcohol interventions in primary care populations. Cochrane Database Syst Rev 2007(8):CD004148.

2. Kaner EF, Dickinson HO, Beyer F, Pienaar E, Schlesinger C, Campbell F, Saunders JB, Burnand B, Heather N: The effectiveness of brief alcohol interventions in primary care settings: a systematic review. Drug and alcohol review 2009, 28:301-323.

3. Jonas DE, Garbutt JC, Amick HR, Brown JM, Brownley KA, Council CL, Viera AJ, Wilkins TM, Schwartz CJ, Richmond EM, Yeatts J, Evans TS, Wood SD, Harris RP: Behavioral Counseling After Screening for Alcohol Misuse in Primary Care: A Systematic Review and Meta-analysis for the US Preventive Services Task Force. Ann Intern Med 2012, 157:645-654.

4. Moyer VA, Preventive Services Task F: Screening and behavioral counseling interventions in primary care to reduce alcohol misuse: US preventive services task force recommendation statement. Ann Intern Med 2013, 159:210-218.

5. Saitz R: Clinical practice. Unhealthy alcohol use. N Engl J Med 2005, 352:596-607.

6. Bradley KA, DeBenedetti AF, Volk RJ, Williams EC, Frank D, Kivlahan DR: AUDIT-C as a brief screen for alcohol misuse in primary care. Alcohol Clin Exp Res 2007, 31:1208-1217.

7. Bush K, Kivlahan DR, McDonell MB, Finn SD, Bradley KA: The AUDIT alcohol consumption questions (AUDIT-C): an effective brief screening test for problem drinking. Ambulatory Care Quality Improvement Project (ACQUIP). Alcohol Use Disorders Identification Test. Arch Intern Med 1998, 158:1789-1795.

8. AUDIT: The Alcohol Use Disorders Identification Test: Guidelines for Use in Primary Care. 2nd edition. http://whqlibdoc.who.int/hq/2001/who_msd_msb_ 01.6a.pdf.

9. Bradley KA, Kivlahan DR, Zhou XH, Sporleder JL, Epler AJ, McCormick KA, Merrill JO, McDonell MB, Fihn SD: Using alcohol screening results and treatment history to assess the severity of at-risk drinking in Veterans Affairs primary care patients. Alcohol Clin Exp Res 2004, 28:448-455.

10. Rubinsky AD, Dawson DA, Williams EC, Kivlahan DR, Bradley KA: AUDIT-C Scores as a Scaled Marker of Mean Daily Drinking, Alcohol Use Disorder Severity, and Probability of Alcohol Dependence in a US General Population Sample of Drinkers. Alcohol Clin Exp Res 2013, 37:1380-1390.

11. Rubinsky AD, Kivlahan DR, Volk RJ, Maynard C, Bradley KA: Estimating risk of alcohol dependence using alcohol screening scores. Drug Alcohol Depend 2010, 108:29-36.

12. Au DH, Kivlahan DR, Bryson CL, Blough D, Bradley KA: Alcohol screening scores and risk of hospitalizations for $\mathrm{Gl}$ conditions in men. Alcohol Clin Exp Res 2007, 31:443-451.

13. Bryson CL, Au DH, Sun H, Williams EC, Kivlahan DR, Bradley KA: Alcohol screening scores and medication nonadherence. Ann Intern Med 2008, 149:795-804.

14. Lembke A, Bradley KA, Henderson P, Moos R, Harris AH: Alcohol screening scores and the risk of new-onset gastrointestinal illness or related hospitalization. J Gen Intern Med 2011, 26:777-782.

15. Williams EC, Bradley KA, Gupta S, Harris AH: Association between alcohol screening scores and mortality in black, hispanic, and white male veterans. Alcohol Clin Exp Res 2012, 36:2132-2140.

16. Harris AH, Reeder R, Ellerbe L, Bradley KA, Rubinsky AD, Giori NJ: Preoperative alcohol screening scores: association with complications in men undergoing total joint arthroplasty. J Bone Joint Surg Am 2011, 93:321-327.

17. Harris AH, Bryson CL, Sun H, Blough D, Bradley KA: Alcohol screening scores predict risk of subsequent fractures. Subst Use Misuse 2009, 44:1055-1069.

18. Bradley KA, Rubinsky AD, Sun H, Bryson CL, Bishop MJ, Blough DK, Henderson WG, Maynard C, Hawn MT, Tonnesen H, Hughes G, Beste LA, Harris AH, Hawkins EJ, Houston TK, Kivlahan DR: Alcohol screening and risk of postoperative complications in male VA patients undergoing major non-cardiac surgery. J Gen Intern Med 2011, 26:162-169.

19. Harris AH, Bradley KA, Bowe T, Henderson P, Moos R: Associations between AUDIT-C and mortality vary by age and sex. Popul Health Manag 2010, 13:263-268.

20. Bradley KA, Maynard C, Kivlahan DR, McDonell MB, Finn SD: The relationship between alcohol screening questionnaires and mortality among male veteran outpatients. J Stud Alcohol 2001, 62:826-833.

21. Kinder LS, Bryson CL, Sun H, Williams EC, Bradley KA: Alcohol screening scores and all-cause mortality in male Veterans Affairs patients. J Stud Alcohol Drugs 2009, 70:253-260. 
22. Bradley KA, Bush KR, Epler AJ, Dobie DJ, Davis TM, Sporleder JL, Maynard C, Burman ML, Kivlahan DR: Two brief alcohol-screening tests from the Alcohol Use Disorders Identification Test (AUDIT): validation in a female Veterans Affairs patient population. Arch Intern Med 2003, 163:821-829.

23. Dawson DA, Grant BF, Stinson FS: The AUDIT-C: screening for alcohol use disorders and risk drinking in the presence of other psychiatric disorders. Compr Psychiatry 2005, 46:405-416.

24. Dawson DA, Grant BF, Stinson FS, Zhou Y: Effectiveness of the derived Alcohol Use Disorders Identification Test (AUDIT-C) in screening for alcohol use disorders and risk drinking in the US general population. Alcohol Clin Exp Res 2005, 29:844-854.

25. Frank D, DeBenedetti AF, Volk RJ, Williams EC, Kivlahan DR, Bradley KA: Effectiveness of the AUDIT-C as a screening test for alcohol misuse in three race/ethnic groups. J Gen Intern Med 2008, 23:781-787.

26. Aertgeerts B, Buntinx F, Ansoms S, Fevery J: Screening properties of questionnaires and laboratory tests for the detection of alcohol abuse or dependence in a general practice population. $\mathrm{Br} J$ Gen Pract 2001, 51:206-217

27. Bischof G, Grothues J, Reinhardt S, John U, Meyer C, Ulbricht S, Rumpf HJ: Alcohol screening in general practices using the AUDIT: how many response categories are necessary? Eur Addict Res 2007, 13:25-30.

28. Gomez A, Conde A, Santana JM, Jorrin A: Diagnostic usefulness of brief versions of Alcohol Use Disorders Identification Test (AUDIT) for detecting hazardous drinkers in primary care settings. J Stud Alcohol 2005, 66:305-308.

29. Meneses-Gaya C, Zuardi AW, Loureiro SR, Hallak JE, Trzesniak C, de Azevedo Marques JM, Machado-de-Sousa JP, Chagas MH, Souza RM, Crippa JA: Is the full version of the AUDIT really necessary? Study of the validity and internal construct of its abbreviated versions. Alcohol Clin Exp Res 2010, 34:1417-1424.

30. Rumpf HJ, Hapke U, Meyer C, John U: Screening for alcohol use disorders and at-risk drinking in the general population: psychometric performance of three questionnaires. Alcohol Alcohol 2002, 37:261-268.

31. Wu SI, Huang HC, Liu SI, Huang CR, Sun FJ, Chang TY, Shih SC, Jeng KS: Validation and comparison of alcohol-screening instruments for identifying hazardous drinking in hospitalized patients in Taiwan. Alcohol Alcohol 2008, 43:577-582

32. Gual A, Segura L, Contel M, Heather N, Colom J: Audit-3 and audit-4: effectiveness of two short forms of the alcohol use disorders identification test. Alcohol Alcohol 2002, 37:591-596.

33. Bradley KA, Williams EC, Achtmeyer CE, Volpp B, Collins BJ, Kivlahan DR: Implementation of evidence-based alcohol screening in the Veterans Health Administration. Am J Manag Care 2006, 12:597-606.

34. Rose HL, Miller PM, Nemeth LS, Jenkins RG, Nietert PJ, Wessell AM, Ornstein S: Alcohol screening and brief counseling in a primary care hypertensive population: a quality improvement intervention. Addiction 2008, 103:1271-1280.

35. Unhealthy Drinking Screening \& Intervention Guideline: Adults. Part 1: Screening and Brief Interventions. https://provider.ghc.org/all-sites/ guidelines/alcohol-adult.pdf.

36. Johnson JA, Lee A, Vinson D, Seale JP: Use of AUDIT-based measures to identify unhealthy alcohol use and alcohol dependence in primary care: a validation study. Alcohol Clin Exp Res 2013, 37(1):E253-E259.

37. Bradley KA, McDonell MB, Bush K, Kivlahan DR, Diehr P, Fihn SD: The AUDIT alcohol consumption questions: reliability, validity, and responsiveness to change in older male primary care patients. Alcohol Clin Exp Res 1998, 22:1842-1849.

38. Grant BF, Dawson DA, Stinson FS, Chou PS, Kay W, Pickering R: The alcohol use disorder and associated disabilities interview schedule-IV (AUDADIS-IV): reliability of alcohol consumption, tobacco use, family history of depression and psychiatric diagnostic modules in a general population sample. Drug Alcohol Depend 2003, 71:7-16.

39. National Institute on Alcohol Abuse and Alcoholism: Helping Patients Who Drink Too Much: A Clinician's Guide (Updated 2005 Edition). Washington, D.C: National Institutes of Health, US Department of Health and Human Services; 2005

40. Wright SM, Craig T, Campbell S, Schaefer J, Humble C: Patient satisfaction of female and male users of Veterans Health Administration services. J Gen Intern Med 2006, 21(3):S26-S32.

41. StataCorp: Stata Statistical Software: Release 11. College Station, TX: StataCorp LP; 2009
42. Levitt A, Schlauch RC, Bartholow BD, Sher KJ: Gender differences in natural language factors of subjective intoxication in college students: an experimental vignette study. Alcohol Clin Exp Res 2013 [Epub ahead of print].

43. Greenfield TK, Kerr WC: Alcohol measurement methodology in epidemiology: recent advances and opportunities. Addiction 2008, 103:1082-1099.

44. Chavez LJ, Williams EC, Lapham G, Bradley KA: Association between alcohol screening scores and alcohol-related risks among female veterans affairs patients. J Stud Alcohol Drugs 2012, 73:391-400.

45. Saha TD, Chou SP, Grant BF: Toward an alcohol use disorder continuum using item response theory: results from the National Epidemiologic Survey on Alcohol and Related Conditions. Psychol Med 2006, 36:931-941.

46. Saha TD, Stinson FS, Grant BF: The role of alcohol consumption in future classifications of alcohol use disorders. Drug Alcohol Depend 2007, 89:82-92.

47. Thompson DC, Rivara FP, Thompson RS, Salzberg PM, Wolf ME, Pearson DC: Use of behavioral risk factor surveys to predict alcohol-related motor vehicle events. Am J Prev Med 1993, 9:224-230.

48. Wechsler H, Davenport A, Dowdall G, Moeykens B, Castillo S: Health and behavioral consequences of binge drinking in college. JAMA 1994, 272:1672-1677.

49. Cherpitel CJ: Alcohol and injuries: a review of international emergency room studies since 1995. Drug and alcohol review 2007, 26:201-214.

50. Dawson DA: Heavy drinking and the risk of occupational injury. Accid Anal Prev 1994, 26:655-665.

51. Dawson DA, Li TK, Grant BF: A prospective study of risk drinking: at risk for what? Drug Alcohol Depend 2008, 95:62-72.

52. Murray RP, Connett JE, Tyas SL, Bond R, Ekuma O, Silversides CK, Barnes GE: Alcohol volume, drinking pattern, and cardiovascular disease morbidity and mortality: is there a U-shaped function? Am J Epidemiol 2002, 155:242-248.

53. Puddey IB, Rakic V, Dimmitt SB, Beilin LJ: Influence of pattern of drinking on cardiovascular disease and cardiovascular risk factrs-a review. Addiction 1999, 94:649-663.

54. Hillbom M, Juvela S, Numminen H: Alcohol intake and the risk of stroke. J Cardiovasc Risk 1999, 6:223-228.

55. Hillbom M, Numminen $H$, Juvela S: Recent heavy drinking of alcohol and embolic stroke. Stroke 1999, 30:2307-2312

56. Klatsky AL, Armstrong MA, Friedman GD: Alcohol and mortality. Ann Intern Med 1992, 117:646-654.

57. Rivara FP, Garrison MM, Ebel B, McCarty CA, Christakis DA: Mortality attributable to harmful drinking in the United States, 2000. I Stud Alcohol 2004, 65:530-536.

doi:10.1186/1940-0640-9-2

Cite this article as: Delaney et al:: Inconsistencies between alcohol screening results based on AUDIT-C scores and reported drinking on the AUDIT-C questions: prevalence in two US national samples. Addiction Science \& Clinical Practice 2014 9:2.

\section{Submit your next manuscript to BioMed Central and take full advantage of:}

- Convenient online submission

- Thorough peer review

- No space constraints or color figure charges

- Immediate publication on acceptance

- Inclusion in PubMed, CAS, Scopus and Google Scholar

- Research which is freely available for redistribution 